\title{
The British Journal for the History of Science
}

http://journals.cambridge.org/BJH

Additional services for The British Journal for the History of Science:

Email alerts: $\underline{\text { Click here }}$

Subscriptions: Click here

Commercial reprints: $\underline{\text { Click here }}$

Terms of use : $\underline{\text { Click here }}$

\section{Unification achieved: William Cullen's theory of heat and phlogiston as an example of his philosophical chemistry}

\section{GEORGETTE Taylor}

The British Journal for the History of Science / Volume 39 / Issue 04 / December 2006, pp 477 - 501 DOI: 10.1017/S0007087406008727, Published online: 10 November 2006

Link to this article: http://journals.cambridge.org/abstract_S0007087406008727

How to cite this article:

GEORGETTE Taylor (2006). Unification achieved: William Cullen's theory of heat and phlogiston as an example of his philosophical chemistry. The British Journal for the History of Science, 39, pp 477-501 doi:10.1017/S0007087406008727

Request Permissions : $\underline{\text { Click here }}$ 


\title{
Unification achieved: William Cullen's theory of heat and phlogiston as an example of his philosophical chemistry
}

\author{
GEORGETTE TAYLOR*
}

\begin{abstract}
William Cullen, lecturer in chemistry at Glasgow and Edinburgh Universities, spent many years formulating his own theory of heat and combustion, the most developed version of which appears in a little-known set of lecture notes of 1765. Cullen's theory is of particular interest to historians of chemistry as an example of his ideal of 'philosophical chemistry', an autonomous branch of natural philosophy distinct from the mechanical philosophy, with its own general laws and explanations of phenomena justified by observation. The theory assimilated Joseph Black's recent discovery of fixed air as well as Cullen's investigations of the generation of heat in chemical operations. It was formulated just one year before British chemists' sudden identification of new 'airs' was dramatically to change the field of phlogiston theory. The theory differs in important ways from any version yet discussed. It successfully brought both heat and elective attraction within its explanatory domain. It set out a causal hierarchy which reversed the usual pattern evinced in earlier sets of lecture notes, subordinating the mechanical to the chemical in the form of Cullen's theory of elective attraction. The paper argues that Cullen was attempting to bring the study of heat as well as combustion within the bounds of his 'philosophical chemistry' by means of his single unifying theory.
\end{abstract}

Thomas Thomson's assessment of William Cullen (1710-90) as 'the true commencer of the study of scientific chemistry in Great Britain'1 has been keenly upheld by modern historians of chemistry. ${ }^{2}$ Cullen's teaching of 'philosophical

* STS Department, UCL, Gower Street, London WC1E 6BT, UK. Email: g.taylor@ucl.ac.uk.

I would like to thank the AHRC, whose funding made this research possible. Also the staff of the Wellcome Library for the History and Understanding of Medicine and the Library of the Royal College of Physicians, Edinburgh, all of whom were unfailingly helpful on every occasion. All manuscript material is quoted by kind permission of these libraries. My thanks for their invaluable advice and constructive criticism are due to all those who read early drafts, but most particularly to Hasok Chang, Anna Simmons and the two anonymous BJHS referees. Thanks also to Simon Schaffer for his encouragement, and to my brother Hamish Ironside for his erudition. Finally, thanks also to my husband for his unflagging and invaluable support.

1 T. Thomson, The History of Chemistry, London, 1830, 304.

2 See, for example, J. R. R. Christie and J. Golinski, 'The spreading of the word: new directions in the historiography of chemistry 1600-1800', History of Science (1982), 20, 235-59; J. Crellin, 'William Cullen: his calibre as a teacher, and an unpublished introduction to his A Treatise of the Materia Medica, London, 1773', Medical History (1971), XV, 79-87; A. L. Donovan, 'William Cullen and the research tradition of eighteenth-century Scottish chemistry', in Origins and Nature of the Scottish Enlightenment (ed. R. H. Campbell and A. S. Skinner), Edinburgh, 1982; J. Golinski, 'Utility and audience in eighteenth-century chemistry: case studies of William Cullen and Joseph Priestley', BJHS (1988), 21, 1-31; D. Guthrie, 'William Cullen M.D., and his times', in An Eighteenth Century Lectureship in Chemistry (ed. A. Kent), Glasgow, 1950, 49-65; S. Shapin, 'The audience for science in eighteenth-century Edinburgh', History of Science (1974), 12, 95-121; W. P. D. Wightman, 'William Cullen and the teaching of chemistry', Annals of Science (1955), 11, 154-65. 
chemistry $^{{ }^{3}}$ inspired the generation of chemists responsible for many of the advances in the understanding of gases, as well as many of the protagonists of the phlogiston debates of the late eighteenth century. These debates were provoked by the discovery and description of gases (or 'airs') by Joseph Black, Joseph Priestley and Henry Cavendish. The 'original' principle of phlogiston had been posited by Georg Stahl long before Cullen began teaching. Stahl's phlogiston was believed to be an elemental fatty earth, the presence of which explained why some substances were combustible and others not. Inflammable substances were so, simply because they contained phlogiston. When combustion took place the phlogiston 'flew off' into the surrounding atmosphere. Although no one ever succeeded in isolating Stahl's phlogiston, the theory continued to develop during the eighteenth century. By the 1770s the suggestion had been made that 'inflammable air' (the gas now known as hydrogen ${ }^{4}$ ) might be the elusive phlogiston. Cullen's teaching career thus straddled the divide between Stahl's initial hypothesis and the various identifications of phlogiston which later emerged.

Cullen himself had many doubts about traditional phlogiston theory ${ }^{5}$ and throughout his career he never hesitated to voice those doubts. Evidence drawn from student lecture notes of the 1760s shows that he formulated a theory of heat and inflammability which offered a new explanation of combustion (or 'inflammation', as he often called it). His theory still postulated a 'phlogiston', but merely as a convenient label pinned to a compound substance composed of two familiar, tangible substances - a stark contrast to the principle of inflammability of Stahlian tradition.

3 On Cullen's philosophical chemistry see A. L. Donovan, Philosophical Chemistry in the Scottish Enlightenment: The Doctrines and Discoveries of William Cullen and Joseph Black, Edinburgh, 1975; Golinski, op. cit. (2); and J. R. R. Christie, 'William Cullen and the practice of chemistry', in William Cullen and the Eighteenth-Century Medical World (ed. A. Doig, J. P. S. Ferguson, I. A. Milne and R. Passmore), Edinburgh, 1993, 98-109.

4 Cavendish implied in 1766 that the inflammable air he had collected was phlogiston in its free state: H. Cavendish, 'Three papers, containing experiments on factitious airs', Philosophical Transactions of the Royal Society of London (1766), 56, 141-84. But it was Richard Kirwan in 1782 who made this explicit claim: R. Kirwan, 'Continuation of the experiments and observations on the specific gravities and attractive powers of various saline substances', Philosophical Transactions of the Royal Society of London (1782), 72, 179-xxxv. At some point around the 1780s it seems to have become clear that more than one inflammable air existed. Adair Crawford specifically referred in 1788 to both 'light inflammable air' and 'heavy inflammable air'. The term 'light inflammable air' apparently referred consistently to hydrogen gas but the referents of the second term varied, being water gas in one case, and carbon monoxide in another. Crawford believed that both airs were different forms of the 'inflammable principle' or phlogiston. See A. Crawford, Experiments and Observations on Animal Heat, and the Inflammation of Combustible Bodies; Being an attempt to Resolve these Phenomena into a General law of Nature, 2nd edn, London, 1788, 359. This distinction was not always observed by chemists and sheds an interesting light on the arguments of Richard Kirwan and Joseph Priestley against the anti-phlogistic theories of Lavoisier.

5 As Perrin has pointed out, a lack of consensus characterized phlogiston theories throughout the century. See C. E. Perrin, 'Research traditions: Lavoisier and the chemical revolution', Osiris (1988), second series, 4, 53-81. Kim has pointed out that much of what is usually regarded as 'classical' phlogiston theory was in fact grafted onto Stahl's original idea of a fatty earth by the French chemist Etienne-François Geoffroy. See M. G. Kim, Affinity, That Elusive Dream: A Genealogy of the Chemical Revolution, Cambridge, MA, 2003, 146-52, 168-73. To simplify matters, I refer to a 'traditional' phlogiston theory which postulated an elemental substance whose presence in a compound conveyed the property of combustibility to that compound. Combustion involved the loss or escape of phlogiston, as did respiration, and on this basis metallic calces were simple substances, while metals were compounds, as of course were all other inflammable substances. 
Cullen's theory seems to have come to its most mature form in 1765, at which time he was lecturing at Edinburgh University and gave an exposition of it to his students. The manuscript notes of these lectures, discussed below, provide a new source of information on Cullen's ideas on heat. Although historians have already noted the presence of Cullen's heat theory in other sets of lecture notes, the scope of the theory contained in this manuscript is wider and the details differ to such an extent that a re-examination of his thinking may be necessary.

Dating from the period between Joseph Black's work on fixed air ${ }^{6}$ and Priestley's and Cavendish's work on factitious airs, ${ }^{7}$ this theory attempted to use new discoveries to solve old chemical problems. Seeking to account for both the mechanical (physical) and chemical phenomena of heat in a single comprehensive hypothesis, the theory explained the generation of heat by invoking an imponderable aether modelled on that of Sir Isaac Newton. It drew on Cullen's work on the generation of heat by chemical combination, complementary work to that set out in his single published paper on chemistry, ${ }^{8}$ as well as on the embryo chemistry of gases. It even achieved Cullen's 'cherished goal' of encompassing elective attraction (also known as chemical affinity) within its bounds. ${ }^{9}$

This remarkable unification prompts the title of this paper. It was achieved by Cullen's inversion of the usual Newtonian causal hierarchy, where the behaviour of gross matter was caused by the movements of an imponderable aether. In contrast, Cullen's theory set the particular elective attractions of gross matter at the top of the causal chain. They were responsible for the behaviour of the aetherial fluid, the movements of which then produced the sensations of heat or cold. Cullen's heat theory can be seen as both a product of and an exemplar for his 'philosophical chemistry', which sought to establish a new status for the practice of chemistry as a science with its own general principles and laws. It reduced the seemingly disparate phenomena of heat generation to just two instances, chemical and mechanical. His postulated theory explained both. It formed an integrated whole, firmly entrenching the study of heat and its related phenomena within the domain of his philosophical chemistry.

\section{The evidence: Cullen's chemistry lectures}

Cullen's theory was never published. It appears only in a set of manuscript lecture notes apparently taken around 1765. A large number of such sets of notes of Cullen's chemistry lectures are extant, and other (probably earlier) versions of the heat theory appear in a few of these manuscripts. It is necessary, therefore, before proceeding to describe the theory in detail, to set it in its historical context.

6 J. Black, 'Experiments upon magnesia alba, quicklime and some other alcaline substances', Essays and Observations Read before a Society in Edinburgh (1756), 2, 157-225.

7 Cavendish, op. cit. (4); J. Priestley, 'Observations on different kinds of air', Philosophical Transactions (1668-1775) (1772), 62, 147-264.

8 W. Cullen, 'Of the cold produced by evaporating fluids, and of some other means of producing cold', Essays and Observations, Physical and Literary (1756), 2, 145-56.

9 J. R. R. Christie, 'Ether and the science of chemistry', in Conceptions of Ether: Studies in the History of Ether Theories 1740-1900 (ed. G. N. Cantor and M. J. S. Hodge), Cambridge, 1983, 85-110, 103. 
Cullen was appointed to the lectureship in chemistry at Glasgow University in 1747, continuing to lecture until 1755 when he moved to Edinburgh University, acting as professor of chemistry from that year until $1766 .{ }^{10} \mathrm{He}$ also held other teaching positions during his time at each university, and indeed continued to teach at Edinburgh as professor of the institutes of medicine and of the practice of medicine until 1789 . Cullen's teaching was enormously influential on the practice and teaching of chemistry in the latter half of the century, both directly and through the later work of his most famous pupil and successor Joseph Black, and other lesser-known students such as George Fordyce, Donald Monro, James Anderson and William Withering. Cullen's role as an improver and educator, ${ }^{11}$ his innovative organization of his courses, ${ }^{12}$ his critical analysis of the work of predecessors, ${ }^{13}$ his use of aether theory ${ }^{14}$ and his innovative development of teaching tools ${ }^{15}$ have all been mentioned when attempting to explain this influence.

Although Cullen's theory remained unpublished in the normal sense of the word, it would have been made known to sufficient numbers through more private channels of communication as to be regarded as an important contribution to the chemistry of heat and inflammability of the latter part of the eighteenth century. The network of British and continental chemical communication centring on Cullen and Black was extensive. ${ }^{16}$ Both Donovan and Golinski have argued that in the context of the Scottish eighteenthcentury university, Cullen's and Black's ideas as expounded in their lectures had effectively been placed in the public domain. ${ }^{17}$ The diarist Sylas Neville, himself a medical student under Cullen, speaks routinely of the copying of lecture notes and of a thriving trade in the sale and purchase of reliable sets of notes. ${ }^{18}$ Likewise, the apothecary and natural philosopher John Elliot admitted to having been able to study a set of Joseph Black's lecture notes belonging to a friend, although he complained that he 'only wished they had been more perfect' ${ }^{19}$

In the case of Cullen's teaching, historians are unusually fortunate that lecture notes dating from throughout his career abound in archive collections. In many cases they are

10 J. R. Partington, History of Chemistry, 4 vols., London, 1961, iii, 128-9.

11 Christie, op. cit. (3).

12 Crellin, op. cit. (2), 83-4.

13 J. R. R. Christie, 'Historiography of chemistry: Hermann Boerhaave and William Cullen', Ambix (1994), 41, 4-19.

14 Christie, op. cit. (9), 97-102.

15 M. Crosland, "The use of diagrams as chemical "equations" in the lecture notes of William Cullen and Joseph Black', Annals of Science (1959), 15, 75-90.

16 See, for example, A. Clow, 'Hermann Boerhaave and Scottish chemistry', in An Eighteenth Century Lectureship in Chemistry (ed. A. Kent), Glasgow, 1950, 41-8, 47-8; T. H. Levere and G. L. Turner, Discussing Chemistry and Steam: The Minutes of a Coffee House Philosophical Society 1780-1787, Oxford, 2002, 4-10; J. A. Cranston, 'Black's influence on chemistry', in An Eighteenth Century Lectureship in Chemistry (ed. A. Kent), Glasgow, 1950, 99-106. See also W. F. Bynum, 'Cullen, William (1710-1790)', in Oxford Dictionary of National Biography (ed. H. C. G. Matthew and Brian Harrison), Oxford, 2004.

17 J. Golinski, Science as Public Culture: Chemistry and Enlightenment in Britain, 1760-1820, Cambridge, 1992, 42-3; Donovan, op. cit. (3), 271.

18 S. Neville, The Diary of Sylas Neville 1767-1788, London, 1950.

$19 \mathrm{~J}$. Elliot, Philosophical Observations on the Senses of Vision and Hearing to which are added, a treatise on Harmonic Sounds, and an essay on Combustion and Animal Heat, London, 1780, 122-3. 
remarkably complete. The collections at Glasgow and Edinburgh Universities, as well as that at the library of the Royal College of Physicians in Edinburgh (RCPE), have been well studied, and have provided a good deal of information on Cullen's teaching practices (see, for example, work by Leonard Dobbin, ${ }^{20}$ A. L. Donovan ${ }^{21}$ and William Wightman ${ }^{22}$ ). In addition to these well-known collections, a smaller but by no means inconsequential collection of lecture notes dating mainly from the latter years of Cullen's career at Edinburgh is held at the Wellcome Library for the History and Understanding of Medicine in London. This collection has been less studied by historians than those held in Scotland, with only a few mentions in the literature. Only J. R. Crellin has published any substantial work on the manuscripts. ${ }^{23}$ This paper draws on evidence primarily from the substantial sets of lecture notes held at the Wellcome Library.

\begin{tabular}{|c|c|c|c|c|}
\hline & Date(s) & MS reference & Student & Contents on heat/inflammability \\
\hline 1 & 1760s & MS79A-C ${ }^{24}$ & Unknown & $\begin{array}{l}\text { Lectures on physical theories of heat and } \\
\text { temperature }\end{array}$ \\
\hline 2 & $\begin{array}{l}\text { February } \\
1765 \text { onwards }\end{array}$ & MS1919-21 $1^{25}$ & Will Falconer ${ }^{26}$ & $\begin{array}{l}\text { Substantial lectures 'On Fire'; chemical and } \\
\text { physical theories based on aether theory }\end{array}$ \\
\hline 3 & $\begin{array}{l}\text { October } \\
\text { 1765-April } 1766\end{array}$ & MS1922 27 & Charles Blagden & $\begin{array}{l}100 \text { lectures from Definitions to Watery } \\
\text { Substances. No lectures specifically on } \\
\text { heat/fire. Aether not mentioned }\end{array}$ \\
\hline
\end{tabular}

Set 2 is a three-volume set of lectures. As the lectures begin some way into the course and are labelled 'Chymistry Part III' it would appear that at least one volume is missing. ${ }^{28}$

20 L. Dobbin, 'A Cullen chemical manuscript of 1753', Annals of Science (1936), 1, 138-56.

21 Donovan, op. cit. (3).

22 Wightman, op. cit. (2); W. P. D. Wightman, 'William Cullen and the teaching of chemistry II', Annals of Science (1956), 12, 192-205.

23 J. Crellin, 'William Cullen and practical chemistry', Actes $d u$ XIIe Congrès internationale d'histoire des sciences, Paris 1968 (1971), 6, 17-21; Crellin, op. cit. (2).

24 W. Cullen, Lectures on Chemistry 1760s (unknown date), Medical Society of London Papers, Wellcome Library for the History and Understanding of Medicine, London, MS/MSL/79a-c.

25 W. Cullen, Lectures on Chemistry 1765 (notes taken by W. Falconer), Wellcome Library for the History and Understanding of Medicine, London, MS1919-1921. The notebooks containing these notes are dated February 1765, and inscribed with the name Will Falconer, then a student of Cullen's. The three extant volumes cover what Cullen usually referred to as 'the Chemical History of Bodies', being a discussion of the substances that were the object of chemistry, classified into Salts, Metals, Inflammables, Earths and Waters.

26 Will Falconer (1744-1824) was registered in Cullen's class from 1765 and graduated MD from Edinburgh in 1766, so these lectures would represent his final year. Practising first in Chester, in 1770 he moved to Bath, where he remained for the rest of his life. FRS 1773, and Physician to the Bath General Hospital from 1784, he published on a wide range of topics. Most of his work was on medicine and chemistry, in particular his work on analysis of the Bath spa waters, but he is also recognized for important work on climate and civilization. I am indebted to my anonymous referees for this last.

27 W. Cullen, Lectures on Chemistry (notes taken by C. Blagden), 1766, Blagden Papers, Wellcome Library for the History and Understanding of Medicine, London, MS 1922.

28 A portion of another set of lectures is held by Clifton College in Bristol, and these are referred to by Wightman (see Wightman, op. cit. (22)) as having belonged to Will Falconer. Although they are titled 'Vol. 1 st', it is unlikely that they form the first volume of this set of lectures. According to Wightman they are dated 1766 and contain a transcript of ninety-six lectures - practically the whole of Cullen's course. Wightman 
It is this set that contains Cullen's 1765 theory of heat. ${ }^{29}$ This paper will draw primarily on this last set, which I shall refer to henceforth as the 'Falconer set'. The discussion 'On Fire' contained therein does not seem to have formed part of the lectures contained in the apparently later Set 3. Why these lectures were not included in the course apparently attended by Charles Blagden must be a matter for conjecture, but the dating of his notes indicates that Cullen missed them out from his course rather than that Blagden wilfully ignored them. ${ }^{30}$

As Donovan has observed, Cullen showed a lifelong interest and concern with the physico-chemical notion of heat and inflammability. Evidence from an earlier set of lectures, also in the possession of the Wellcome Library (MS79A-C) (Set 1 above), suggests that he had been developing his hypotheses on fire and heat for some years. The lectures devoted to heat in this set focus to a greater extent on the physical concepts of heat and temperature, and it is clear that the mature theory of heat and phlogiston contained in the Falconer set was still only half-formulated at this date. Donovan has briefly noted the presence of what was perhaps an earlier formulation of the theory, ${ }^{31}$ in a set of lecture notes held at the Royal College of Physicians, Edinburgh ${ }^{32}$ which he is unable to date more precisely than to suggest that they were taken during the 1760s (the library catalogue dates them at 1755). Christie makes use of the same RCPE MS in his discussion of the role of aether in the causal explanation of attraction between particles of matter. ${ }^{33}$ The details suggest that these notes also date from earlier than the Falconer set, which given the avoidance of the aether in the Blagden lectures would seem to represent the most advanced and highly developed theories that Cullen felt able to pass on to his students. The contents of these lectures form the basis of what follows. ${ }^{34}$ I first give a brief account of Cullen's ideal of philosophical chemistry before setting out in

suggests that this volume is in fact a transcript of an earlier set of lectures acquired by Falconer for his own use after his graduation. I have unfortunately been unable to gain access to these to examine them to date.

29 Cullen, op. cit. (25).

30 It is clear from the format of Blagden's notes that he did not simply miss these lectures, as he did note down the contents of each lecture. As he dated each and every lecture to which he took notes and these notes became progressively more comprehensive throughout the course, it is apparent that there are no gaps large enough to explain the omission except by ascribing it to Cullen himself. It seems from both the Falconer set and Set 1 that where Cullen did include his theory of Fire, it was inserted between the lectures on the bodies classed as 'inflammables' and on those classed as metals. In Blagden's lecture notes there is only a single day between these two parts of the course, which argues that Cullen did not include his theory in that year's course.

31 Donovan, op. cit. (3), 59-60, 152-3.

32 W. Cullen, Lectures on Chemistry c. 1755? (undated), Library of the Royal College of Physicians, Edinburgh, MS Cullen 10.

33 Christie, op. cit. (9), 99-101.

34 Although the lectures follow on from those that form the bulk of the volume in which they appear, even to the extent of having been introduced by Cullen at the end of his 'history of the inflammable bodies', the handwriting of the lectures on fire changes noticeably from earlier in the volume. The most noticeable characteristic of the lectures on fire is that they are a great deal neater and give the impression of being more carefully set down, perhaps from a set of rough notes. The notes only ever cover one side of any sheet of paper throughout the volume. A number of comments are inserted on the opposing sheets, again in different handwriting and possibly at a different time. The contents of the lectures accord with what we know of Cullen's theories of heat and with other sets of lecture notes examined. 
more detail his 1765 theory of heat. This provided the necessary explanatory context for his phlogiston theory, which I describe in full before attempting to assess the historical significance of Cullen's speculations.

\section{The ideal: Cullen's philosophical chemistry}

Cullen's ideal of 'philosophical chemistry' is a complex notion and warrants some detailed explanation. The term suggests a rational thoughtful science, a respectable liberal art with strong theoretical foundations. At the same time, however, as Christie and Golinski have argued, Cullen's baptism of his subject as 'philosophical chemistry ${ }^{\mathbf{3}_{5}}$ was to some extent a social stratagem. In invoking an image of a 'liberal science', 36 respectable and useful to industry and philosophy as well as to medicine, ${ }^{37}$ Cullen's lectures put forward a new role for the chemical philosopher in a consulting capacity as an 'improving citizen'. ${ }^{38}$ Such a discipline would be an appropriate, and indeed valuable, study for gentlemen and the sons of gentlemen. This useful respectable philosophical chemistry was clearly distinguished from the activities of the 'sooty empirics', ${ }^{39}$ the chemical artisans. But while emphasizing the role of theory in his chemistry Cullen had to strike a careful balance, shunning the groundless speculations of fanatics whose unfortunate 'enthusiasms' were to be decried. As Cullen revealingly told his students in 1766, 'it appears now that $\mathrm{Ch}^{\mathrm{y}}$ can be studied without enthusiasm; but tho' Chymists may have ceased to be Fanatics, Fanatics have not ceased to be Chemists, which appears evident by the Hutchinsonians of the present time' ${ }^{40}$ For Cullen it was essential that any theory be the product of empirical generalization, for no theory could be founded on anything other than observation. Indeed, historians have often commented from the evidence of his lectures that he did not prescribe the excessive use of theory in his teaching of chemistry. ${ }^{41}$

35 Cullen, op. cit. (27), Lectures 4 and 7. Cullen did not regard himself as the instigator of philosophical chemistry, citing Boyle in particular, Boerhaave and Newton. He complained that 'Sir Isaac Newton likewise thought $\mathrm{Ch}^{\mathrm{y}}$ well worth his care, and the some volumes of his on that Subject are invidiously withheld from the world'. A predecessor he did not specifically cite, but whose lectures may well have influenced the young Cullen, was Peter Shaw, whose 1733 Lectures propounded 'the discovery of Physical Axioms, and Rules of Practice for producing useful effects, in the way of a Philosophical Chemistry'. See P. Shaw, Chemical Lectures, Publickly read at London, in the years 1731, and 1732; and Since at Scarborough, in 1733 for the Improvement of Arts, Trades and Natural Philosophy, London, 1733, 1.

36 John Robison's phrase, quoted in J. R. R. Christie, 'The origins and development of the Scottish scientific community, 1680-1760', History of Science (1974), 12, 122-41, 135.

37 See, in particular, Golinski, op. cit. (17), 17-25; Christie, op. cit. (13) and Christie, op. cit. (3).

38 Christie, op. cit. (3), 101.

39 R. Boyle, The Sceptical Chymist or Chymico-Physical Doubts \& Paradoxes, touching the Spagyrist's Principles Commonly called the Hypostatical; as they are wont to be Propos'd and Defended by the Generality of Alchymists, 1st edn, London, 1661, 24.

40 Cullen, op. cit. (27), Lecture 7. A remark that replicates this comment almost verbatim is cited by Christie from a Glasgow University MS which he dates to 1757-8. See Christie, op. cit. (13), 15. It would seem that the revelatory emphasis of the followers of John Hutchinson exercised Cullen's mind considerably.

41 See e.g. Donovan, op. cit. (3). 
The lectures 'On Fire' ${ }^{\prime 2}$ contained in the Falconer set of lectures epitomize Cullen's ideal of philosophical chemistry. Cullen explained his decision to enter into a theoretical consideration of heat thus: "the Philosophy of Particular Qualities is the business properly of Philosophic Chemistry \& we promised in the Introduction to our Course to enter sometimes into theoretical Enquiries'. ${ }^{43}$ The discussion which follows is overtly speculative but a close examination shows that the speculations were based on observation and empirical generalization. The lectures display a sometimes rather precarious balance between the approved Baconian empiricism and a desire to fashion chemistry into a philosophical science concerned with the study of general principles. Donovan has noted Cullen's particular care to demarcate chemistry from other parts of natural philosophy as a 'distinct science'. ${ }^{44}$ In all his lectures Cullen carefully set out his own definition of chemistry as 'that part of Natural Philosophy which treats of the particular properties of matter'. ${ }^{45}$ This is contrasted with the mechanical philosophy envisaged as dealing with the more general properties of bodies, such as shape ('figure'), mass, extension and motion. Cullen offered two examples of this distinction, both of which appear in almost all of the extant notes of his lectures. His first example was of a wedge, which ' is always considered as one of the mechanical powers, $\&$ as properly a subject of mathematical enquiry, when considered abstractedly as made of any matter you please'. ${ }^{46}$ The abstract wedge shape was thus the concern of the mechanical side of natural philosophy. But on considering a wedge with a particular purpose, in the form of a razor or knife (Cullen used both examples),

having a very acute Angle, sharpe edge \& one that will not break, but that by its flexibility

$\&$ elasticity will bend to a moderate force, $\&$ then recover itself: such a wedge cannot be made of any Matter indifferently, but must be formed from some particular mass that has these 'qualities'; as Iron; $\&$ is therefore a subject of Chy. ${ }^{47}$

This case illustrated Cullen's view that the object or 'office' of chemistry was 'to induce new qualities on bodies, and take away old ones'. ${ }^{48}$

The second example distinguished between mechanical and chemical methodologies, using the example of a mixture of chalk and sand. This mixture could be separated mechanically by adding water (the chalk remaining suspended while the sand sank to the bottom), or chemically by the addition of vinegar (which would dissolve the chalk by elective attraction but would not combine with the sand). ${ }^{49}$ 'Mechanical' methods made use of those properties of which all matter was possessed, simply by virtue of being material. 'Chemical' methods involved the combination and separation of

42 The MS is not foliated and as the course is not divided into individual lectures it is difficult to cite references. In order to provide a full citation I have counted pages from the first page of the notes 'On Fire'. These occupy the final quarter of the bound volume, and most pages are separated by a blank sheet. These too I have included in the pagination. The notes begin on $\mathrm{f} .1 \mathrm{r}$.

43 Cullen, op. cit. (25), MS1920, f. 1r.

44 Donovan, op. cit. (3), 55.

45 Cullen, op. cit. (27), Lecture 9.

46 Cullen, op. cit. (27), Lecture 9.

47 Cullen, op. cit. (27), Lecture 9.

48 Cullen, op. cit. (27), Lecture 19.

49 This example appears in both Cullen, op. cit. (27), Lecture 9, and Cullen, op. cit. (24), f. 6. 
substances through the judicious exploitation of the chemist's two key agents: elective attraction and heat. These agencies particularized substances, drawing on those powers and properties that they possessed as individuals.

Theories of elective attraction originated with a paper read by the Frenchman Etienne François Geoffroy to the Académie royale des sciences in $1718 .^{50}$ Such theories dealt with the relative tendencies of particular substances to combine. ${ }^{51}$ Tables of elective attraction ordered these tendencies, which could then be harnessed to promote combination or separation of the desired substances. The archetypical separation by elective attraction exploited the power of attraction to decompose a compound substance by the addition of a third:

Among bodies that have Elective Attractions, it may be taken as a general Rule, that two only will unite at the same time, if therefore a third be added that be more strongly attracted by either of them, the less attracted is separated, \& this third is joined with the other in its place. On this account it is called Elective; as choosing the one $\&$ defending the other. ${ }^{52}$

Key to Cullen's own theory of elective attraction was the tenet that substances that combined lost their old properties and acquired entirely new ones as a compound substance. This contrasts with the belief of the French Stahlians, notably Pierre Joseph Macquer, that the properties or 'qualities' of a compound substance were in some way a product of the properties of its constituents. Cullen based his opposition to this concept on his own observations:

I formerly gave a table, exhibiting a comparison between the acid \& alkali of nitre, and the neutral produced; from which it appears very improbable that qualities can be inherent: nay the very name neutral (which is derived from the manifest destruction of the qualities of each) contradicts such a supposition. ${ }^{53}$

In Cullen's chemistry, the properties of bodies could thus be changed by separating and combining them, taking advantage of their particular elective attractions.

The action of heat similarly served to assist combination as well as to foster separation. The 'philosophers by fire ${ }^{54}$ were well named. Cullen classified chemical

50 E. F. Geoffroy, 'Tables des differents rapports observés en Chimie entre differentes substances', Histoire (et Mémoires) de L'Académie royale des sciences (1719), 1718, 202-12; E. F. Geoffroy, 'Enclaircissements sur la table inserée dans les mémoires de 1718 concernant les rapports observés entre differentes substances', Histoire (et Mémoires) de L’Académie royale des sciences (1720), 20-34.

51 The origins of elective attraction (or affinity) and its development in France have been studied at some length. See U. Klein, 'The chemical workshop tradition and the experimental practice: discontinuities within continuities', Science in Context (1996), 9, 251-87; idem, 'The origin of the concept of chemical compound', Science in Context (1994), 7, 163-204; idem, 'E. F. Geoffroy's table of different rapports observed between different chemical substances - a reinterpretation', Ambix (1995), 42, 79-100; Kim, op. cit. (5). The most comprehensive survey of affinity tables throughout Europe is A. M. Duncan, Laws and Order in EighteenthCentury Chemistry, Oxford, 1996. Cullen took a key role in the extension and dissemination of theories of elective attraction, particularly in his attempt to formalize cases of double elective attraction through the use of diagrams and rudimentary formulae. See Crosland, op. cit. (15).

52 Cullen, op. cit. (27), Lecture 21.

53 Cullen, op. cit. (27), Lecture 72.

54 J. Locke, An Essay Concerning Human Understanding, new edn carefully revised, and compared with the best copies, 6th edn, London, undated, 447. 
processes under three headings of solution, fusion and exhalation, listing separate processes of fermentation, precipitation, digestion, maceration, circulation, putrefaction, deliquescence, congelation, eliquation, vitrification, calcination, de-calcination, cementation, evaporation, crystallization and distillation. Only a very few of these did not involve heat in any way. Most operations relied on both elective attraction and heat for their success, and knowledge of the general principles of each were the desiderata of Cullen's philosophical chemistry.

As might be expected, given the high profile of elective attraction in his lectures, Cullen drew heavily on the work of the French natural philosophers of the Académie royale des sciences. ${ }^{55} \mathrm{He}$ enthusiastically adopted and extended Geoffroy's Table des rapports from sixteen to an impressive thirty-one columns, ${ }^{56}$ a table unsurpassed in scope until Torbern Bergman's Disquisitio de Attractionibus Electivis of $1775 .^{57}$ The chemistry of salts established by Homberg, and extended by Louis Lemery and Rouelle, ${ }^{58}$ also loomed large in Cullen's lectures, although (as indicated above) his understanding of the subject differed somewhat from theirs. In 1753 Cullen presented his own thoughts on neutral salts to the Philosophical Society of Edinburgh ${ }^{59}$ and although he published nothing on this issue, a small part of his teaching on neutral salts was later to be published (and extended) by his student Donald Monro in $1768 .^{{ }^{60}}$ While this variety of influences is apparent in Cullen's lectures, he did not go so far as to adopt any particular matter theory on their authority. Cullen's preferred ontological notions of elements or principles are not in fact made very clear in his lectures. $\mathrm{He}$ recommended a Humean scepticism to his students on this subject, advising them instead to concentrate on the limit of chemical analysis, ${ }^{61}$ an operationally defined entity which he sometimes dubbed the 'chemical element' ${ }^{62}$ But in spite of his frequent recommendations of caution to his students, the 1765 speculations 'On Fire' do shed significant light on Cullen's preferred ontological schema. This assumed a broadly dualistic form, distinguishing ordinary gross matter from a hypothesized Newton-style

$55 \mathrm{Kim}$ has drawn attention to the fact that knowledge of much of Stahl's work was mediated through Geoffroy and the other French chemists. Cullen undoubtedly drew much from the work of Geoffroy and his contemporaries, and it is impossible to tell whether those aspects of Stahlianism that are evident in his teaching emanated from this French influence or from Stahl's own works. See Kim, op. cit. (5) 146-51.

56 The MS under study includes an example of Cullen's 31-column affinity table. See Cullen, op. cit. (25), MS 1921.

57 T. Bergman, 'Disquisito de attractionibus electivis', Nova Acta Regiae Societatis Scientiarum Upsaliensis (1775), 2, 161-250.

58 On the chemistry of salts see F. L. Holmes, Eighteenth-Century Chemistry as an Investigative Enterprise, 1989; idem, 'Analysis by fire and solvent extractions: the metamorphosis of a tradition', Isis (1971), 62, 128-48. Lemery's work may also have influenced Cullen's pragmatic ontological recommendations; Kim has shown that Lemery's work on analysis by fire led him to remove the investigation of principles from the domain of chemistry. See Kim, op. cit. (5) 129-32.

59 Dobbin, op. cit. (20).

60 D. Monro, 'An account of some neutral salts made with vegetable acids, and with the salt of amber; which shews that vegetable acids differ from one another; and that the salt of amber is of a particular kind, and not the same with that of sea salt, or of vitriol, as alledged by many chemical authors', Philosophical Transactions of the Royal Society of London (1767), 57, 479-516.

61 See, for example, Cullen, op. cit. (24), f. 17.

62 W. Cullen, Chemistry Lecture Notes 1760-65, British Library, MS Add 17229-71230, MS 71229 f. 3. 
aether. ${ }^{63}$ Even so, there is little evidence of any allegiance to any particular system of chemical principles or elements anywhere in Cullen's lectures. In this context, the doubtful chemical principles of the French Stahlians appear only as taxonomic families in an irreproachable system of classification, dividing substances into salts, inflammables, metals, earths, waters and (later) airs.

Stahl's influence can nevertheless be distinguished, particularly in Cullen's earlier lecture courses. Here he referred to the Stahlian hierarchy of matter, divided into principles, mixts, compounds and aggregates, ${ }^{64}$ although even then he rejected much of the hierarchy as of little practical use to his students. This limitation may have been inspired by the pragmatic or analytical idea of simplicity presented in the works of mineralogists such as Johann Andreas Cramer and Axel Fredrik Cronstedt, both of whom were regularly cited in Cullen's lectures. Porter has shown that these ideas first arose in German mineralogy out of a practice-driven need to accept 'the fact that miners could derive no benefit from an understanding of the composition of ores that went beyond what could be established in the assayer's furnace' ${ }^{65}$ Cullen too elevated practical need above purely theoretical ideas, and by 1766 was rejecting the Stahlian distinction between mixts and compounds (a mixt being composed of two elements combined, while a compound consisted of two mixts combined), preferring to elide Stahl's classes: 'such order can be traced in very few \& we use the terms Mixt $\&$ Compound indiscriminately to signify a Body combined of any matters possessing different qualities'.66

In Cullen's rather utilitarian system, the words 'element' and 'principle' were applied interchangeably (but, as he admitted, without precision) to 'any very simple sort of Matter which enters into the Composition of several other Bodies'. ${ }^{67}$ All bodies were to be considered 'either as mixts or as aggregates', a demarcation that reflected his distinction between chemical and mechanical methodology. Here Cullen adopted Stahl's division of matter into integrant and constituent parts, ${ }^{68}$ a distinction also adopted by Peter Shaw and Pierre-Joseph Macquer, ${ }^{69}$ as an illustration of the difference between matter as aggregate (as divided mechanically) or mixt (divided chemically). ${ }^{70}$ The distinction served to buttress his operational notions of compound substances as being divisible by chemical means into simpler substances with different properties or qualities.

63 Interest in Newton's aetherial speculations had been revived by the publication of B. Robinson, $A$ Dissertation on the Aether of Sir Isaac Newton, Dublin, 1743. Christie has noted the similarity of Cullen's aether theory to that appearing in Robinson's Dissertation. Christie, op. cit. (9).

64 See, for example, W. Cullen, Lectures on Chemistry, probably 1748/9 (vol. 1 of MS catalogued as Lectures on Materia Medica), Library of the Royal College of Physicians, Edinburgh, MS Cullen 15, Lecture IV. For further information on the identification and dating of this MS see Wightman, opera cit. (2) and (22).

65 T. M. Porter, 'The promotion of mining and the advancement of science - the chemical revolution of mineralogy', Annals of Science (1981), 38, 543-70, 544.

66 Cullen, op. cit. (27), Lecture 18.

67 Cullen, op. cit. (27), Lecture 18.

68 Kim, op. cit. (5) 173.

69 See Shaw, op. cit. (35); P.-J. Macquer, Dictionary of Chemistry (tr. James Keir), London, 1771.

70 See, for example, Cullen, op. cit. (24), 19. 
It seems that the overtly pragmatic and empirical trend of Cullen's lectures may have been a consequence rather of necessity than of preference. He often bemoaned the insufficiency of time and material, meaning the current state of chemical philosophy, that required his course to follow 'the analytic method'71 rather than the synthetic proper to chemistry's scientific status. ${ }^{72}$ Forced to accept the analytic methodology as the only one open to him, for the majority of his course he proceeded along strictly Baconian lines of observation and induction. ${ }^{73}$ This was tempered, however, by the favoured practice of arguing from analogy ${ }^{74}$ as well as by the inclusion of a few empirically founded general principles which underpinned the whole of his course. Cullen's 'general principles' were not, as might be expected, the customary system of metaphysical principles or elements. Theories of elective attraction and heat were the general principles that Cullen set at the foundation of his philosophical chemistry. These principles were concerned more with the dynamics of chemical behaviour than with the ontology of matter. As the agents of chemical change, they might in some sense be regarded as chemical instruments. This is why Cullen was so concerned to formulate a coherent theory of heat that could be integrated into his philosophical chemistry. Heat, like elective attraction, was a chemical tool, and for chemistry to be truly philosophical, a chemical theory of heat was required.

\section{The context: Cullen's theory of heat}

Before we can begin to examine Cullen's phlogiston theory, it is necessary to explain his theory of heat. This section follows the course of Cullen's arguments and explanations as set out in the Falconer lectures. Much of his thinking was based on inductive reasoning conforming to Bacon's prescription, enumerating heat phenomena as in Bacon's 'table of existence and presence ${ }^{75}$ and drawing conclusions from this. It is necessary here substantially to condense Cullen's fairly extensive observations in order to concentrate fully on his theoretical inferences. These postulated a dualistic ontology of matter and aether that enabled him to explain the generation of heat, whether through animal, vegetable, mechanical or chemical action. The heat theory reduced these four classes of action to only two: mechanical and chemical action, with the heat in each case being generated by the interaction between the two different types of matter. Importantly, as the next section shows, it also allowed him to reclassify

71 For Cullen, the 'analytic method' required him to 'range the several productions of Nature \& art in separate classes, \& examine the chymical properties of each'. The synthetic method effectively would have reversed the process. Cullen, op. cit. (27), Lecture 10; also Cullen, op. cit. (25), MS 1920, f. 1v.

72 In Set 1 (see above) Cullen specifically objected to the definitions of chemistry offered by Homberg, Macquer, Boerhaave and Shaw on the grounds that the 'fundamental Error in all their Definitions lies in calling Chemistry an Art, whereas it is necessary to consider it as a Part of Science'. Cullen, op. cit. (24), f. 2.

73 In his lectures on metals in his 1766 course, Cullen did adopt the synthetic method, explaining the properties of metals (malleability, fusibility, specific gravity, colour etc.) as general principles before briefly covering the specific elective attractions between metals. See Cullen, op. cit. (27), Lectures 91-3.

74 Argument from analogy was sanctioned by Locke for use in reflection on those unobservable causes of sensible effects as 'the only help we have'. See Locke, op. cit. (54), 565.

75 F. Bacon, The New Organon (1620), Cambridge, 2000, 110-11. 
combustion (and, by implication, phlogiston) in more prosaic terms as a simple case of chemical action.

Cullen began by pointing out the need for a new consideration of the subject, as 'there is no subject concerning which Phylosophers have spoke more, than that of Fire, and none that they have thrown less light upon' ${ }^{76}$ Having thus damned the majority of his predecessors, he discussed various definitions gleaned from philosophers including Bacon, Boyle, Newton and, of course, Boerhaave. Cullen did not forbear to criticize authorities whom he felt were unreliable in particular areas. In spite of his reputation, as Christie has noted, ${ }^{77}$ Boerhaave was a regular target of Cullen's censure. He dismissed the celebrated work on fire, citing as 'extraordinary' the fact that Boerhaave had inferred the presence of fire in snow. ${ }^{78}$ Since in Cullen's view it was impossible in the current state of knowledge to begin with a definition of fire, he offered instead 'some mark by which we can always judge of its presence, absence, Increase and Decrease' ${ }^{79}$ Rejecting Boerhaave's decision to denote expansion as the 'universal mark of fire' ${ }^{80}$ he defined 'Fire as a power which excites in us the sensations of Heat and Light' ${ }^{81} \mathrm{He}$ set out his plan to cover first the generation of heat, ${ }^{82}$ then its communication and finally the general effects of fire. ${ }^{83}$

Cullen distinguished carefully between the communication of heat and its generation: 'the giving Heat to Bodys which shew'd no mark of it before, without any Evident Communication with any other that is heated already' ${ }^{84}$ For the benefit of his students, he proceeded to enumerate various methods of generation of heat in order to come to a conclusion concerning its cause. He began with the mechanical generation of heat, itemizing various instances where heat was generated through the application of physical force: through attrition, percussion or collision. He listed the types of substance from which heat could be generated by attrition (dry, hard bodies), the correspondingly negative instances (such as fluids) ${ }^{85}$ and the instances of greatest efficiency (hard and rough substances), and noted the fact that one of the substances needed to be 'fixed' or immovable. He concluded that heat was 'produced in consequence of certain Vibrations Tremors or Oscillatory motions excited in the particles of Bodies' ${ }^{\mathbf{8 6}}$

76 Cullen, op. cit. (25), MS1920, f. 1r.

77 Christie, op. cit. (13), 12-13.

78 Cullen, op. cit. (25), MS1920, f. 3r.

79 Cullen, op. cit. (25), MS1920, f. 3r.

80 Cullen, op. cit. (25), MS1920, f. 3r.

81 Cullen, op. cit. (25), MS1920, f. 3v.

82 Somewhat confusingly, given his Lockean definition of fire as the power to excite the sensation of heat, Cullen also stated stated that in the following discussion he would use the words 'fire' and 'heat' interchangeably unless specifically distinguished.

83 The lecture notes cease at the conclusion of his consideration of the generation of heat and light - the communication of heat and effects of fire remain unconsidered in their specifics, although they are dealt with to some extent within the discussion of generation.

84 Cullen, op. cit. (25), MS1920, ff. 5r-5v.

85 As an example of his reasoning, Cullen denied that the agitation of fluid mercury produced heat, arguing that it was necessary for the fluid mercury to change to black powder before the agitation of this produced the heat sensed.

86 Cullen, op. cit. (25), MS1920, f. 13v. 
After a somewhat unproductive attempt mathematically to relate the vibrations on which the generation of heat depended to momentum and velocity, surface area and 'locomotive power', ${ }^{87}$ Cullen returned to his Baconian role. He argued from the generation of heat by the attrition of various metals that heat was generated according to their relative hardness. Cullen offered as an example the fact that steel generated more heat than iron by virtue of its increased hardness. ${ }^{88}$ Thus 'heat does not depend on the presence of a peculiar matter present only in certain Bodys and entering into their mixture, but on the motions excited in Bodys as aggregates'. ${ }^{89}$ But Cullen's investigation had still not made it clear whether

these motions from whence the Heat springs are in the Solid parts of the Body, or in a subtile Fluid filling their Pores, but not entering into their composition, nor confined to any particular kind of matter, but present between the Solid parts of all Bodies. ${ }^{90}$

The term 'subtile Fluid' was something of a catch-all in this period. Stephen Hales had used it in reference to the 'Air' that he discovered was emitted from various substances ${ }^{91}$ and William Lewis used it for the tangible but volatile liquid 'called by the chemists aether' (ether). ${ }^{92}$ Yet other philosophers suggested that light, electricity and magnetism were this type of substance. Finally it could stand for the imponderable, invisible and intangible substance that some held filled the universe, christened somewhat confusingly by Newton the 'aether' and analogous to what Descartes even more confusingly had called the element of 'fire'. ${ }^{93}$

Christie has drawn attention to Cullen's postulation of an aether ${ }^{94}$ as evidenced by another set of lecture notes dating from the 1760 s and held at the RCPE. ${ }^{95}$ The theory set out in these notes related the expansion and contraction of ordinary matter when heat was added or lost to the addition or loss of aether. This version of Cullen's aether was hypothesized as possessing a 'repellent power' ${ }^{\mathbf{9 6}}$ which, Cullen suggested, might also be the cause of the attractions between gross matter. As Christie notes, this hypothesis unfortunately failed to account for the elective nature of chemical attraction. ${ }^{97}$

87 Cullen, op. cit. (25), MS1920, f. 15r.

88 This was not an entirely fortuitous observation by Cullen, particularly in the light of the phlogiston theory he set out later in the lectures. According to Macquer the difference between steel and iron was that steel contained a greater proportion of phlogiston. See, for example, P.-J. Macquer, Elements of the Theory and Practice of Chemistry, 2nd edn, London, 1764, 64.

89 Cullen, op. cit. (25), MS1920, ff. 17r-17v.

90 Cullen, op. cit. (25), MS1920, f. 17v.

91 S. Hales, Vegetable Staticks (first published 1727), London, 1969, 90.

92 W. Lewis, 'Experimental examination of platina', Philosophical Transactions (1757), 50, 156-66, 161.

93 While Newton's aether was specifically mentioned by Cullen his own aetherial preference seems to lean rather towards a similar conceptualization to that of Lemery and Homberg in France and, later, of Boerhaave. Benjamin Franklin's explanation of electricity by reference to a subtle fluid may well have provided further inspiration. See R. Fox, The Caloric Theory of Gases from Lavoisier to Regnault, Oxford, 1971, 11-15.

94 See Christie, op. cit. (9), 86. Although Christie refers to 'ether', I have followed the Falconer MS in spelling 'aether' to signify the postulated imponderable subtle fluid.

95 Cullen, op. cit. (32).

96 Cullen, op. cit. (32), f. 86.

97 The theory put forward in this MS did not endeavour to extend its scope to cover combustion or phlogiston theory. 
An aether theory could explain the motion of particles towards each other but was unable to explain why some particles would part to join other particles, apparently in preference. This was a problem that would have been familiar to Newton, as well as to countless other philosophers. The Falconer set of lectures shows that Cullen did eventually reach some form of accommodation with the problem and this accommodation is outlined in the details of his 1765 heat theory.

The theory described in this Falconer set of lectures, like that of the RCPE set cited by Christie, relied on a hypothesized aether. Citing the observation that heat could be communicated in vacuo, ${ }^{98}$ supported by analogy with the phenomena of electricity and magnetism, Cullen contended that 'certain Oscillatory motions in a subtle Fluid such as we have mentioned is the cause of heat and that the motion of the Solid parts only act in communicating motion to it'. ${ }^{99}$

While some (Cullen specifically mentioned Boyle, Bacon and Newton) tended towards the view that heat was the motion of the particles of ordinary matter and yet others such as Stahl, Musschenbroek and Homberg were predisposed towards the idea that heat inhered in a particular matter entering into the composition of bodies as mixts, Cullen's own position was distinct from either of these, midway between what we might call, with some apologies to Robert Schofield, 'mechanism' and 'materialism': 100

From the first we Differ in supposing a peculiar universal present, Elementary Matter of Fire, From the Second in believing that this matter never enters into the mixture of Bodies, nor is confined to any Particular sett of Bodies. N.B. As Sir Isaac Newton first started the Notion of this Subtle Fluid, and called it an Aether we shall also for the future apply that name to it. ${ }^{101}$

Taking all this into account, Cullen concluded that

Fire consists in certain Oscillatory motions excited in a Subtle Elastic Fluid, present everywhere in Bodies interposed betwixt the particles of them and filling their Pores never entering into their composition as Mixts but Capable of passing into and from them, in greater or less quantity without altering their Mixture. ${ }^{102}$

So at the centre of Cullen's theories of heat and fire we have a concept of heat as caused by the oscillation of an aether which did not itself enter into any sort of combination with ordinary matter. Heat was generated mechanically by the communication of motion to this aether.

Cullen's theory was by no means simple in its relations of aetherial motion, quantity and heat. His aether

98 Cullen does not enter into discussion of this assertion, which he cites in terms that imply an accepted fact established by experiment. Joseph Black apparently referred at this point in his lectures to an experiment of Newton's mentioned in query 18 of Opticks. See J. Black, Lectures on the Elements of Chemistry delivered in The University of Edinburgh; by the Late Joseph Black M.D., first American from the last London edn, 3 vols., Philadelphia, 1807, i, 22-3.

99 Cullen, op. cit. (25), MS1920, f. 17v.

100 R. E. Schofield, Mechanism and Materialism: British Natural Philosophy in an Age of Reason, Princeton, 1970.

101 Cullen, op. cit. (25), MS1920, ff. 21v-23r.

102 Cullen, op. cit. (25), MS1920, ff. 21r-21v. 
is always in different quantitys in different Bodies and the heat is as the quantity of it present, joined to the motion ... the increase of motion in the parts of a Body is always attended with a Communication of more of this fluid to it, or an Accumulation of it in it, So that tho' the heat depends on the quantity of it present, as well as on the motion, yet as the quantity is always as the motion, we may conclude that the degree of Heat generated will always be as the motion. ${ }^{103}$

We might somewhat anachronistically compare this three-way relationship with that of the ideal gas laws where temperature, pressure and volume of a gas are all related. Likewise, change in temperature, quantity of aether and oscillation were related to each other. Consequent upon or at least concurrent with the increase in motion of the aether was a 'communication' or 'accumulation' in its quantity, the increase in temperature being, it would seem, a product of both.

Cullen's rather tortuous relation of the quantity of aether to its motion might well flow from an implicit distinction between quantity and intensity of heat, a distinction formalized in Black's concept of specific heat. ${ }^{104}$ An aether that did not itself combine with ordinary matter would in many ways match Black's notion of heat that could enter and 'hide' within ordinary matter as it changed state. On the other hand, it might simply derive from Cullen's desire to account for changes in the physical state of aggregation on heating, as he had done in the RCPE manuscript already cited. In the 1765 lectures Cullen did not specifically touch on the expansion of heated bodies but it seems likely that he felt that the accumulation of aether might be responsible for the expansion. In any event, no reference to either latent or specific heat has been found in any of Cullen's lectures and no such explicit inference is drawn in the Falconer set.

Having examined the physical phenomena of heat and fire, Cullen had succeeded in setting down the high-level theory that formed the basis of his ontology of heat. $\mathrm{He}$ drew conclusions that accorded to some extent with the mechanistic, corpuscularian philosophy yet were also dependent on certain qualitative differences between the two postulated kinds of matter. The distinction was not, however, drawn along the usual lines of active as opposed to passive matter. While the aether was active in the sense that its increased oscillation caused the sensation of heat, it is notable that such increased oscillation was itself instigated by the motion of ordinary matter. Unusually, this hierarchy of causes would seem to favour ordinary matter as the ultimate cause of heat through its stimulation of the aether. Although Cullen returned to his Baconian induction as he proceeded to discuss the chemical generation of heat, this qualitative distinction between ordinary matter and aether was further emphasized and his implicit causal hierarchy persisted.

Chemists had long been aware that when certain substances were mixed together they often produced either heat or cold. As Cullen acknowledged, Musschenbroek had already studied the matter and had produced tables showing these combinations.

103 Cullen, op. cit. (25), MS1920, ff. 19r-19v.

104 McKie and Heathcote have established that Joseph Black had developed his ideas on specific heat in 1760 and on latent heat shortly after that. By 1765 Black's work on specific heat and latent heat would probably have been known to Cullen, although it is not mentioned in extant lecture notes: D. McKie and N. H. de V. Heathcote, The Discovery of Specific and Latent Heats, 1935, 35. 
Cullen also produced generalizations of such tables, examples of which appear in the lecture notes. Thus combinations of acids with alkalis ${ }^{\mathbf{1 0 5}}$ and alkalis with inflammables ${ }^{\mathbf{1 0 6}}$ produced heat, while combinations of water and ice and ice with alcohol ${ }^{\mathbf{1 0 7}}$ produced cold. A decade earlier Cullen had published his findings that the 'exhalation of vapour'108 ${ }^{\text {generated cold. }}{ }^{109}$ 'Exhalation' included not only physical vaporization and evaporation but the chemical production of fixed air, as for example in the mixture of absorbent earth with a weak acid in vacuo. Cullen argued that the 'air' separated from the earth was so rarefied in the vacuum as to generate sufficient cold to overwhelm the heat normally generated by the combination of acid and earth. Similarly, the common factor in Cullen's table of cooling combinations seemed to be the rarefaction of one of the combining substances, whether through a physical change of state or through the solution of a solid substance. ${ }^{110}$ On the basis of these observations, he asked, was it not the case that 'exhalations generate cold, or that cold is produced from the Rarefaction of Bodies? Does not this also render the Converse probable? Viz. that Condensation generates heat'.111

'Condensation', like rarefaction, was apparently used in a simple, almost naively volumetric, sense: when a mixture took place the 'bulk' of the product would be less than the total 'bulks' of the substances unmixed. The evidence of his tables let Cullen argue that when substances were combined in a mixture, heat was produced, and when combined in solution, cold. ${ }^{112}$ This important distinction between 'mixture' and solution was based on empirical grounds linked to his theory of elective attraction: ${ }^{113}$

In solution there is no change of qualities in the 2 united Bodys, except it be that a solid Solvend is rendered Fluid. In Mixture the Separate properties of each are lost, and the Compound acquires new qualities distinct from either, these again disappear on Decomposition, and the 2 Ingredients assume their original properties. ${ }^{114}$

A mixture took place as a result of chemical attractions between the two substances. These attractions were also presumably responsible for the hypothesized

105 Cullen, op. cit. (25), MS1920, f. 29v.

106 Cullen, op. cit. (25), MS1920, f. 31v.

107 Cullen, op. cit. (25), MS1920, f. 33r.

108 Cullen, op. cit. (25), MS1920, f. 41r.

109 Cullen, op. cit. (8).

110 British chemists of this time often did not distinguish between physical and chemical phenomena in their discussions of heat. See D. R. Dyck, 'The nature of heat and its relationship to chemistry in the eighteenth century’ (Ph.D. thesis AA167 16929), University of Wisconsin, 1967, 220-1.

111 Cullen, op. cit. (25), MS1920, f. 43r.

112 Cullen's conclusion from his experiments that 'every mixture generates heat, and that every solution generates cold' had also appeared in a much earlier paper that he read to the Literary Society in the College of Glasgow, reprinted in Thomson's biography. The implication is that he formulated this part of his theory of heat perhaps as early as 1753-5. J. M. D. Thomson, An Account of the Life, Lectures and Writings of William Cullen M.D., Edinburgh and London, 1859, 53, 580-3.

113 Cullen referred specifically to 'proper Chymical Combination', which was confined to solution or mixture. He took care to exclude 'that improper kind of Combination called Mechanical Diffusion' from his argument.

114 Cullen, op. cit. (25), MS1920, f. 51v. 
'condensation'. Drawing on his hypothesis that the motion of the aether was the cause of heat, Cullen extended its range to cover chemical heat generation:

shall we not then ascribe the heat in mixture to certain motions which must be excited in the Subtile Aether in consequence of such Condensation while on the other hand the Cold generated by Solution, may proceed from some opposite affection of this Fluid. ${ }^{115}$

He drew an analogy with the vibration of strings under differing tensions, where those under greater tension excite faster vibration in air. Cullen suggested that combined substances, thus condensed substances, would excite faster vibrations in the 'aether of fire', ${ }^{116}$ hence generate a greater amount of heat. He had earlier coupled increased oscillation of the aether with its 'accumulation', presumably an increase in its density. In the RCPE set of lectures he explained the reverse process:

as an elastic cord when it receives a stroke, has quicker Vibrations According to the increase of tension; so is heat Occasioned by the Oscillations of an Elastic fluid, the vibrations will be fewer, in proportion to the diminution of density of that fluid by the rarefication of the air, and Consequently a generation of Cold may be effected. ${ }^{117}$

This seems to contrast with Christie's description of Cullen's aether. He explains that the theory stated that 'in mixture, condensation took place, releasing ether (identified with the matter of fire) and raising temperature. In solution, rarefaction occurred, absorbing ether and lowering temperature'. ${ }^{118}$

The theory Cullen expounded in the Falconer set (as well as that contained in RCPE MS Cullen 10) is rather more complex than a simple identification of aether with heat. In the Falconer set, particularly, Cullen seems to have been more concerned with the density of aether within the bounds of the bodies being mixed. Here the condensation of gross matter consequential upon chemical mixture seemingly led to an increase in the density of the aether rather than to its release. Historians' understanding of Cullen's aetherial theorizing may need to be revised to take into account this development in his thinking. From the violin-string analogy, it seems that the causal chain was linked from condensation of matter (and consequent increase in density of aether) to heat generated (via an increase in aetherial oscillation). This hierarchy replicated that drawn from Cullen's consideration of mechanical generation of heat and was further upheld in his discussion of combustion.

\section{Phlogiston: Cullen's version}

Cullen's theory of the generation of heat offered two modes of generation: the mechanical and the chemical. Most instances of heat generation could be ascribed to one or other mode. Cullen devoted a portion of 'On Fire' to the generation of heat in the animal and vegetable kingdoms, endeavouring to explain the production of heat in

115 Cullen, op. cit. (25), MS1920, f. 57r.

116 Cullen, op. cit. (25), MS1920, f. 57v.

117 Cullen, op. cit. (32), f. 323.

118 Christie, op. cit. (9), 99. 
fermentation as well as the 'animal heat' produced in respiration. In both cases he concluded that the heat was chemically generated by the combination of substances in mixtures. Concluding his lectures, he came to develop his hypothesis further to cover combustion. Cullen insisted that this was also a case of the chemical generation of heat.

Although Cullen persuasively argued for the existence of the all-pervasive 'aether of fire' acting by its vibration in all substances, this was clearly different from the matter of inflammability. While the former produced the sensation of heat in all substances without differentiation, the latter was presumed to be the reason why some substances are inflammable and others are not. Cullen was careful to distinguish between the two: 'The Chymists have reason here to speak of a Phlogiston, But that only as the matter of Inflammation, not of Fire.' 119

According to Cullen's previously articulated heat theory, a matter of inflammability or phlogiston would be a particular type of matter present only in certain substances, capable under appropriate circumstances of exciting the aether to oscillation. Cullen did not deny the existence of this phlogiston, nor that it might be transferred from one substance to another in ordinary chemical mixtures and combinations. But he did deny the view of phlogiston as a metaphysical 'principle ${ }^{120}$ of inflammability, stressing instead its common workaday nature.

For Cullen, the search for phlogiston took place firmly in the world of ordinary matter. He explained that he suspected, from the fact that it has never been got by itself' ${ }^{121}$ that it must be a compound substance. ${ }^{122}$ This might seem an odd conclusion, but perhaps justified by Cullen's theory of elective attraction. One tenet of this theory was that two substances ordinarily reluctant to combine could be made to do so through the mediation of a third substance. ${ }^{123}$ The fact that the phlogiston could not be 'got by itself' may have suggested to Cullen that it was one of these types of compound substance that required a third constituent in the mixture to hold it together. Moreover, Cullen's philosophical chemistry required an empirical justification for all theoretical assertions; his phlogiston theory was no exception. Instead of assuming the existence of a substance that had never actually been isolated, he re-examined the phenomena, looking for those substances that could be 'got' from inflammable substances by

119 Cullen, op. cit. (25), MS1920, f. 72v.

120 In this regard he was apparently rejecting the French Stahlian 'principalist' notion that the properties of bodies were dependent on the properties of their constituents, their 'principles'. I follow Kim in the choice of spelling. For a full discussion of 'principalist' chemistry see Kim, op. cit. (5).

121 Cullen, op. cit. (25), MS1920, f. 72v.

122 Only a year later Henry Cavendish was to make public his discovery and investigation of the inflammable air claimed to be the elusive phlogiston. See Cavendish, op. cit. (4). Cavendish implied in this paper that the inflammable air he had collected was phlogiston in its free state, but it was Richard Kirwan in 1782 who made this explicit claim. See Kirwan, op. cit. (4). In this regard also see Cullen's own comment in the Falconer set when listing those substances that he classes as 'inflammables' that 'it has been imagined however that we may add to these an inflammable vapour or air. But I believe this only differs from Oils or Ardent Spirits as the Vapour of Water does from Liquid Water. I will not however positively assert that there is not an Inflammable Air which is permanently in that Form.' Cullen, op. cit. (25), MS1919, f. 243 (Falconer had begun to number the pages in this first volume, but stopped at $\mathrm{f}$. 91 . I have continued the numbering in the same way).

123 See Cullen, op. cit. (27), Lecture 90. 
ordinary chemical processes. He found not a single substance but two, both of which were consistently found to be constituents of inflammable bodies.

Drawing on his own observations he pointed out that ${ }^{124}$

We find that all Inflammable Bodys contain an Acid, a Body in itself not Inflammable. ... This is plain from the resolution of oil, sulphur, ardent spirits and Phosphorus. ... the Vitriolic Acid with a small quantity of oil will form a much greater quantity of [sulphur]. ${ }^{125}$

Next to this is a marginal note: 'By what process does it appear that Zinc, a mixture of Lead and Tin, and other metallic substances which are highly inflammable contain an acid.' ${ }^{126}$ The 'resolution' that Cullen referred to was of course achieved by heat or fire. All these inflammable bodies were apparently analysed into the various acids. Sulphur reduced to vitriolic acid and phosphorus was similarly known to 'contain' an acid. He seems here to have been arguing that the addition of a small amount of an inflammable substance to vitriolic acid would synthesize a much greater 'quantity' of sulphur than the original acid. These statements epitomize the then difficulty in ascertaining the relative simplicity of different substances. Cullen's argument makes little sense unless it is assumed that by 'quantity' he meant something other than weight. Given his prior emphasis on condensation and rarefaction, he was perhaps referring to a reduction in 'bulk'. The critical reader (apparently thinking in terms of weight) noted this apparent anomaly: 'On $y^{\mathrm{e}}$ contrary the Sulphur is allways much less than even the acid employ'd and from a small quantity of Sulphur, we can obtain a much larger portion of Vitr ${ }^{\mathrm{c}}$ acid.' ${ }^{127}$ This point is analogous to an oft-cited inconsistency of phlogiston theory: metallic calces, purportedly the more simple substances, weighed more than the metals from which they were reduced. ${ }^{128}$ Cullen's line of reasoning on inflammables thus far accorded with the Baconian methodology of his earlier consideration of the generation of heat. Having shown to his own satisfaction that all inflammables contain an acid, he continued, 'But there is also another matter present in them always. This is what causes (according to the Chymists) the Inflammation and is the Foundation of Inflammability. ${ }^{129}$ This was the traditional notion of phlogiston and would seem to match the canonical Stahlian formulation: all inflammable substances contain an entity

124 At this point we find notes affixed in the margin of the manuscript, possibly by Will Falconer himself, although there is no way to confirm this. The level of knowledge demonstrated suggests a sophistication which would imply that they were inserted some little while later in his career. From the content of the comments, they were likely to have been added within twenty years. To this unknown commentator at least, Cullen's arguments were no longer satisfactory. I have included such remarks of the marginal commentator as are of particular interest.

125 Cullen, op. cit. (25), MS1920, ff. 72v-74r. Throughout the MS Falconer made use of the common symbols for chemical substances, including phlogiston. Where these appear I have used the full textual description in square brackets.

126 Cullen, op. cit. (25), MS1920, f. 74r.

127 Cullen, op. cit. (25), MS1920, f. 73v.

128 Jean Rey, as early as 1630, published an essay on the increase of weight in lead on calcination, and throughout the eighteenth century solutions were suggested to this anomaly. For a full discussion of the debate see D. McKie and J. R. Partington, 'Historical studies on the phlogiston theory - II. The negative weight of phlogiston', Annals of Science (1938), 3, 1-58.

129 Cullen, op. cit. (25), MS1920, f. 74r. 
that makes them so. But in Cullen's hypothesis that entity was a combination of an acid and some other component.

This is to reach the crux of Cullen's theory:

This other component part of the [phlogiston] I imagine a Mephitic Air, For in the same manner as the acid, we find that it is evolved and reabsorbed in the Vinous Fermentation, and all Burning Bodies exhibit such air, that is it has the same properties with other Mephitic Air, in destroying Fermentation, Animal Life and Inflammation itself. ${ }^{130}$

Recall that Cullen was writing before Cavendish and Priestley had isolated their various 'factitious airs' and after Black had published his paper on fixed air, which chemically differentiated it from common atmospheric air. Cullen's 'mephitic air' referred to an air possessed of all the properties he lists. In 1765 this would have been identified with Black's 'fixed air'. ${ }^{131}$ However, the gaseous referent of each term was unlikely to be identical in all situations. A mere ten years later the term 'mephitic air' would become theoretically contentious, as more than one alternative air to the common had been described and a number of them possessed the qualities listed. But in the circumstances in which Cullen was writing, with the knowledge then available, his inference was not unreasonable.

Where did this leave phlogiston? To take one viewpoint, that of Cullen himself, if phlogiston were not a simple substance then what Cullen was talking about was no longer phlogiston: 'Now if this be allowed what is become of the Chymical Principle of Inflammation, - There is no such Body the [phlogiston] consists of 2 component parts neither of which are of themselves Inflammables. ${ }^{132}$ Cullen thus dispensed with the principalist phlogiston of tradition, replacing it with a compound body composed of two ordinary substances in combination. One might ask why, if it were the mephitic air that caused the inflammability, as Cullen had previously stated, he did not simply identify this as his 'phlogiston'. That would be to oversimplify Cullen's thinking. Joseph Black had shown mephitic (or fixed) air to be present in many 'mixts' that were not combustible, such as the calcareous earths and the milder alkalis. Only those substances that contained both mephitic air and acid were inflammable and only those substances could be said to contain phlogiston.

Further enlightenment on this point comes courtesy of the marginal commentator, who here turned to elective attraction to argue, in much the same way as Richard Kirwan was to argue against Lavoisier's oxygen theory, ${ }^{133}$ that Cullen's idea must fall at this first hurdle: 'They can't be mephitic air and acid because we know $\mathrm{y}^{\mathrm{t}} \mathrm{y}^{\mathrm{y}}$ do not unite. ${ }^{134}$ In the table of elective attraction which Cullen was at this stage presenting to

130 Cullen, op. cit. (25), MS1920, f. 74v.

131 Indeed, in his 1766 lectures, Cullen briefly discussed the 'aerial' class of bodies, dividing them into only two forms, 'Common and Mephitic'. Cullen, op. cit. (27), Lecture 17.

132 Cullen, op. cit. (25), MS1920, f. 74v.

133 R. Kirwan, An Essay on Phlogiston and the Constitution of Acids (first published 1789), London, 1968.

134 Cullen, op. cit. (25), MS1920, f. 75r. Will Falconer became extremely familiar with the behaviour and properties of mephitic air in his later career as a Bath physician. Maehle has shown how Falconer introduced a solution of salt of tartar impregnated with fixed air as a cure for urinary calculi, explaining its action as resulting from the type of double elective attraction that he was taught by Cullen. See A. H. Maehle, Drugs on 
his students there was indeed a column for fixed air, which did not impute any attraction between that air and any acid. ${ }^{135}$ This point may suggest a misunderstanding of Cullen's thinking. Cullen's compound phlogiston was still incapable of being 'got by itself'. The two constituent substances only united through the mediation of another, presumably incapable of remaining combined without this third party. The fact that mephitic air and acid could not be combined on their own thus supported Cullen's theory rather than falsifying it. Nevertheless, the comment testifies to the power of theories of elective attraction throughout the eighteenth century. The note implies that elective attraction was seen to be more fundamental to chemistry and far better attested than any theory of inflammability; conflict between the two principles would always resolve in favour of the former.

Cullen's explanation of the action of his phlogiston in producing inflammation similarly enshrined elective attraction as the most fundamental general principle of his philosophical chemistry: 'To me indeed Inflammation seems to depend on the decomposition of this Compound by the Common Air, which attracts the Mephitic Air. '136 So inflammation was reclassified as simply a normal case of elective attraction, along the lines of the classical model. A substance with a greater attraction to one of the constituents of a combined body than that constituent's attraction for the substance(s) with which it was already combined had the power to decompose the combined body. Cullen's argument was founded on his observation that combustion would not take place in vacuo and on his inference that air was necessary to inflammation. He explained this by assuming that combustion necessarily involved the combination of mephitic air with common air by the action of elective attraction. For this type of separation and recombination by elective attraction to take place, the third substance must be brought into contact with the combined body. As the mephitic air must be attracted by common air for decomposition to take place, then common air must be required for inflammation.

Cullen even had an answer for those who might respond that the inflammation of nitre was capable of being performed in vacuo. In such cases, 'there is as much common air sett loose from the Body as is necessary to dessolve the Mephitic Air which also flies off from it'. ${ }^{137}$ Would it not, however, be obvious if such a deleterious matter were really produced during combustion? Cullen again returned to his theory of elective attraction and his understanding of chemical combination: 'this is easily Obviated if we reflect that Common Air is a proper menstruum of it, and by uniting in the way of mixture with it Destroys its peculiar propertys'. ${ }^{138}$ So Cullen's idea was that combustion took place when the mephitic air contained in the 'phlogiston'-containing body

Trial: Experimental Pharmacology and Therapeutic Innovation in the Eighteenth Century, Amsterdam and Atlanta, GA, 1999, 93-105.

135 Cullen, op. cit. (25), MS1921, ff. 219v-220r. For citations referring to this third volume of the Falconer set which, like its fellows, does not contain folio numbers, I have counted each leaf from the beginning of the volume.

136 Cullen, op. cit. (25), MS1920, f. 74v.

137 Cullen, op. cit. (25), MS1920, f. 74v.

138 Cullen, op. cit. (25), MS1920, f. 76r. 
was attracted to common air with which it united, forming a 'proper mixture' and generating heat. The acid part of the compound seemingly remained with the substance being burned:

The Inflammability of bodies is owing to the Resolution of a Compound, (for which we shall return the name of a Phlogiston) consisting of an $\mathrm{y}^{\mathrm{d} 139}$ and Mephitic Air, and that this resolution is effected by the Elective Attraction of the Common Air, assisted by the Action of Heat, that the Heat generated under Inflammation is to be attributed to the new Combination that takes place, and that therefore after all we are to refer this to the generation of heat by Combination. ${ }^{140}$

Although he did not explicitly refer to his postulated aether in connection with this theory of inflammability, the heat generated was clearly seen as a consequence of the 'condensation' of matter produced by the mixture of mephitic air and common air. Cullen had earlier argued that a similar process was occurring in respiration. ${ }^{141}$ His hypothesis also accounted for the calcination of metals, implying that mephitic air combined in metallic substances was released on inflammation to combine with the common air. ${ }^{142}$ In his 1766 lectures Cullen speculated that only the mephitic air portion of phlogiston was contained in metals. This notion was supported by the fact that mild calcareous earths could restore a calcinated metal just as well as the more usual inflammable substances. ${ }^{143}$ It still remained unclear why there was an undoubted increase in weight on calcinations. ${ }^{144}$ Cullen speculated that as the mephitic air was lost, something else might be added.

There are of course arguments that could be marshalled against Cullen's theory. He did not deal with the increase in weight of those substances that have been burned. The details of his theory when applied, for example, to metals are inconsistent. In addition, the connection between the theory and the more physical effects of heat is far from

139 This appears to be an unusual abbreviation of the word 'acid'. More familiar is the use of the ' $y$ 'shaped rune thorn (P) for the phoneme 'th', resulting in the abbreviations ' $\mathrm{y}^{\mathrm{t}}$, ' $\mathrm{y}$ ', ' $\mathrm{y}^{\mathrm{y}}$ ' and the more mundane ' $y$ ', It is possible that this was simply a phonetic extension of this usage.

140 Cullen, op. cit. (25), MS1920, f. 80r.

141 Cullen, op. cit. (25), MS1920, ff. 70r-70v.

142 It is unclear what, if any, other constitutive substances combined to make inflammables, although Cullen shed some light on this in his 1766 course where, although the theory was not set out in the same form of Baconian induction that was presented to his 1765 students, it was mentioned in passing throughout the course: 'Every inflammable seems to be a combination of acid \& mephitic air; this cannot be proved in any particular instance, but appears probable if the whole history of phlogiston be taken together; $\&$ the different forms of alkohol, oil \& sulphur seem to depend on some small difference in the proportions; there being least acid in alkohol, more in oils, most of all in the more compleat phlogiston of sulphur.' Cullen, op. cit. (27), Lecture 81 .

143 Cullen, op. cit. (27), Lecture 92.

144 In Wellcome MS1922, Cullen argues that it is impossible that the increase in weight could come from the air, as calcination takes place and the usual weight is gained by the metal 'in close vessels', where the air does not have free access. This is odd, although it is important to note that he refers to 'close' vessels, not to calcination 'in vacuo'. We can only assume that he is speaking of cases where the calcination takes place with the benefit of such air as is contained in the vessel, but without allowing the air 'free access'. Those historians concerned by the slowness of chemists to realize that the air is fixed in calcination would do well to note this contemporary confusion. Equally, however, it is surprising that Cullen did not pick up on this point himself, particularly so long after Boyle’s air pump experiments in vacuo. Cullen, op. cit. (27), Lecture 92. 
clear. Cullen considered the physical state of the substances involved to be vital to elective attraction, declaring that for combination to take place one substance at least must be in a fluid state. Insofar as the state of aggregation was related to heat and to aetherial behaviour, this presumably connected the phenomena, but the details are unclear. In this lecture set, the only clue to his thinking at the time is contained in a short lecture that seems to conclude the course. The lecture was devoted to his table of elective attractions. He explained that

The power of Heat may probably increase the Power of Attraction between bodies that are separate \& lessen the attraction between those that are combined. We may hence see how dangerous it is to draw general Principles till experiments have been made on all the different bodies in all their different Circumstances. ${ }^{145}$

Although this accounted for the fact that heat was often required to initiate chemical combination, including combustion, it is difficult to dovetail this phenomenon into the phlogiston theory outlined in 'On Fire', and Cullen did not make the attempt.

In this evolution of the theory, in contrast to earlier theories cited by Christie, ${ }^{\mathbf{1 4 6}}$ Cullen made no attempt to assign any form of aetherial explanation to elective attraction. The earlier attempts noted by Christie attempted to use the variable density of the aether within and outside bodies to explain attraction. In the hypothesis of the Falconer set, the sequence was reversed: combination was due to elective attraction as the proximate cause of the movements of the aether that in turn produced the sensation of heat. Elective attraction was established at the top of the causal hierarchy, initiating the generation of heat by combination. While this did not solve the problem of explaining elective attraction, it made any such explanation unnecessary. Within the bounds of Cullen's philosophical chemistry elective attraction did not need to be explained; its action only needed to be understood. In the new context of Cullen's heat theory the possession of a table of elective attraction, together with a modicum of theory, gave the philosophical chemist the ability to manipulate both heat and matter.

\section{Phlogiston rehabilitated and unification achieved}

By the 1760s the phlogiston theory was attempting to answer more questions than those with which it had been originally formulated to cope. From its original conception, the hypothesized substance had accumulated inconsistent and often contradictory powers and functions. The very notion of a principle of inflammability conflicted with Cullen's understanding of matter and chemical combination. Substances were unable to carry their properties through into chemical mixture, yet the French Stahlian principle of inflammability required just that. Similarly, it required the rational chemist to believe in an imponderable substance released from inflammables on combustion and transferred from one combination to another in chemical operations, yet impossible to isolate. The

145 Cullen, op. cit. (25), MS1921, f. 223r.

146 Christie, op. cit. (9) - the manuscripts cited are RCPE MS Cullen 15 and RCPE MS Cullen 10 (op. cit. (32)). 
philosophical chemistry that Cullen sought to impart to his students had no place for such a body.

Inspired by his desire to establish a philosophical chemistry founded on empirically sanctioned general principles, Cullen re-examined the phenomena of heat and combustion and attempted to formulate an integrated and coherent theory. Cullen's investigations into the generation of heat when certain substances were mixed together provided a link between his empirically based understanding of chemical combination and the mechanical generation of heat. He found that the action of chemical attraction or affinity generated heat, as did the mechanical hammering of iron. To explain both, he hypothesized another imponderable substance that by its oscillation caused the sensation of heat but which was unable to combine with ordinary matter. This aether was itself at the mercy of the more familiar material substances whose movements, combinations and separations could provoke that subtle fluid to produce the sensation of heat.

With the boundaries thus redrawn, a theory of inflammability could be formulated that answered the same questions dealt with by the traditional phlogiston, while avoiding many of the problems. Cullen's combination of mephitic air and acid provided a phlogiston that was at least more material than the alternative version, and certainly held out hopes for its isolation. The existence of this phlogiston was justified by empirical observation, as required by the ideal of a philosophical chemistry. The transfer and decomposition of the material 'phlogiston' in chemical combination and resolution could now be invoked in chemical explanation with impunity. The principalist notions of the French Stahlians were rejected in favour of a theory that classified combustion as simply another instance of elective attraction. Phlogiston was rehabilitated as an ordinary, tangible, compound body, acting and being acted on as any other chemical substance.

Cullen's reversal of the causal hierarchy of the Newtonian aether conferred the dominant role on ordinary gross matter acting mechanically through physical manipulation or chemically through the operation of elective attraction. The philosophical chemist was now possessed of a unified theory and a table of elective attraction. This new chain of command gave him effective control, appropriate to his status, over the general principle of heat. 